\author{
D. Klein · F. Barbé-Tuana - A. Pugliese $\cdot$ H. Ichii • \\ D. Garza $\cdot$ M. Gonzalez $\cdot$ R. D. Molano $\cdot$ C. Ricordi · \\ R. L. Pastori
}

\title{
A functional CD40 receptor is expressed in pancreatic beta cells
}

Received: 17 August 2004 / Accepted: 31 August 2004 / Published online: 3 February 2005

C) Springer-Verlag 2005

\begin{abstract}
Aims/hypothesis: Despite differences in function and embryonic origin, pancreatic islet cells and neurons express proteins belonging to the tumour necrosis factor receptor superfamily. While neurons express the CD40 receptor, it is unknown whether islet cells also express it. We investigated CD40 expression in human and mouse pancreatic islets as well as in NIT-1 insulinoma cells. Methods: CD40 expression was studied by reverse transcriptase polymerase chain reaction, flow cytometry, immunohistochemistry and western blot. Responses mediated by CD40 were assessed by a luciferase gene reporter assay following stimulation with a CD40 agonist antibody. Results: We found that CD40 is expressed in mouse and human pancreatic islet cells. CD40 is expressed by beta cells, and its expression is upregulated by proinflammatory cytokines (IL- $1 \beta$, IFN- $\gamma$ and TNF- $\alpha$ ). CD40 signalling in NIT-1 insulinoma cells activates nuclear factor kappa-B, demonstrating that CD40 is functional. Conclusions/ interpretation: We present evidence that, in addition to immune cell types, mouse and human pancreatic beta cells express CD40. Its expression is upregulated by proinflammatory stimuli, and signalling through this receptor activates NF- $\mathrm{kB}$. We suggest that the effects of inflammatory stimuli that affect beta cell function and survival may be also mediated by signalling through the CD40 receptor. Thus, CD40 may have a role in processes associated with islet autoimmunity and transplantation.
\end{abstract}

Keywords Beta cells · CD40 - Diabetes mellitus · Islets · NIT-1 · Nuclear factor kappa-B

D. Klein · F. Barbé-Tuana $\cdot$ A. Pugliese $\cdot$ H. Ichii $\cdot$ D. Garza · M. Gonzalez · R. D. Molano · C. Ricordi · R. L. Pastori $(\bowtie)$ Diabetes Research Institute,

University of Miami School of Medicine,

$1450 \mathrm{NW} 10$ th Avenue,

Miami, FL, 33136, USA

e-mail: rpastori@med.miami.edu

Tel.: +1-305-2435349

Fax: +1-305-2434404
Abbreviations 7-AAD: 7-Aminoactinomycin D - APC: Allophycocyanin - APC: Antigen-presenting cell $\cdot$ CD40L: CD40 ligand - FITC: Fluorescein isothiocyanate - IEQ: Islet equivalent - LCMV: Lymphocytic choriomeningitis virus $\cdot \mathrm{mAb}$ : Monoclonal antibody $\cdot \mathrm{NF}-\mathrm{kB}$ : Nuclear factor kappa B - NG: Newport green - NOD: Nonobese diabetic $\cdot T_{\mathrm{m}}$ : Melting temperature $\cdot$ TNFR: Tumour necrosis factor receptor

\section{Introduction}

The CD40 receptor is a membrane glycoprotein that belongs to the tumour necrosis factor receptor (TNFR) family. Its natural ligand, CD40 ligand (CD40L or CD154), is a type II transmembrane protein and a member of the TNF- $\alpha$ protein family [1-3]. CD40 is expressed on the surface of $B$ lymphocytes and antigen-presenting cells (APCs) and mediates costimulatory signals for T-lymphocyte activation [4]. During the course of an immune response, the T-cell receptor recognises the MHC/antigen on the surface of APCs. Antigen recognition is followed by the expression of CD40L on T lymphocytes. The interaction of CD40L with CD40 upregulates the expression of other costimulatory molecules on the surface of APCs. These include CD80 and CD86 [5, 6], which interact with CD28 expressed by $T$ cells $[4,7]$. This cascade of events results in IL-2 production and T-cell activation. The critical role of CD40 in T-cell activation is well recognised also in the fields of transplantation [8-11] and autoimmunity $[12,13]$, and it has been confirmed using transgenic and knockout mice [14]. Interference with the CD40 pathway using blocking antibodies against CD40L inhibits the spontaneous development of diabetes in nonobese diabetic (NOD) mice and prolongs allogeneic islet graft survival in nonhuman primates in the absence of conventional immunosuppressive drugs [11, 13]. Similar findings have been obtained in other transplantation settings [8-10]. Moreover, the engagement of CD40 with its ligand CD40L can dramatically affect B lymphocyte survival, leading to either cell proliferation or death depending on whether stim- 
ulation is caused by foreign or self-antigens [15, 16]. CD40/CD40L have a role in isotype switching and somatic hypermutation as well [14]. CD40 expression has been reported in diabetogenic $\mathrm{T}$ cells and T-cell clones in the NOD mouse [17].

Non-immune cell types such as endothelial cells [18], thymic epithelial cells [19], neurons [20], normal and neoplastic thyroid cells [21], carcinomas [22], transformed cell lines [23] and pancreatic duct cells also express CD40 [24]. The effects of CD40 signalling in non-immune cell types are not fully understood. However, several reports indicate that signalling through the CD40 receptor can induce survival $[25,26]$ or growth inhibition and enhances apoptosis of various non-immune cell types [27, 28].

Despite differences in function and embryonic origin, both pancreatic islet cells and neurons express proteins belonging to the TNFR superfamily, such as TNF-R1 and neuron growth factor receptor [29-33]. Since neurons express CD40, we hypothesised that islet cells can also express this member of the TNFR superfamily. In this study we investigated CD40 expression in mouse and human pancreatic islets and the NIT-1 insulinoma cell line.

\section{Methods}

Tissues and cells We studied pancreata and islets from C57BL/6, BALB/c and NOD mice. Human islets were obtained from a pancreatic cadaver donor. NIT-1 insulinoma cells were obtained from the American Type Culture Collection (CRL 2055; ATCC, Manassas, VA, USA) and cultured according to ATCC instructions.

Islet isolation Methods for islet isolation from human and mouse pancreata have been previously described [34, 35]. Human islets were provided by the cGMP facility at the Diabetes Research Institute, University of Miami, and isolated following the automated method developed by Ricordi et al. [34]. Mouse islets were isolated as follows. Animals were sacrificed under general anaesthesia, the abdomen was opened, and the pancreas was exposed and injected with $0.8 \mathrm{mg} / \mathrm{ml}$ collagenase solution (SigmaAldrich, St Louis, MO, USA) through the main bile duct until full distension was achieved. The University of Miami Animal Care and Use Committee approved this procedure. The distended pancreatic tissue was then surgically removed and immersed in collagenase solution. Digestion was performed at $37^{\circ} \mathrm{C}$ for $17 \mathrm{~min}$ with gentle shaking. The enzyme kinetics were sharply slowed by adding cold Hanks' balanced salt solution supplemented with $10 \%$ fetal bovine serum (Hyclone, Logan, UT, USA). Mechanical disruption of the digested pancreatic tissue was achieved by repeated passages through a 14-gauge needle until complete release of free islets was observed under the microscope. The tissue was then filtered through a $450-\mu \mathrm{m}$ screen. Islets were purified by centrifugation at $900 \mathrm{~g}$ for $11 \mathrm{~min}$ on discontinuous Euro-Ficoll gradients. This method routinely provided islets of $>90 \%$ purity as assessed by dithizone staining (Sigma-Aldrich). Islets were counted and scored for size. An algorithm was used for the calculation of $150-\mu \mathrm{m}$-diameter islet equivalent number (IEQ). Experiments were performed using handpicked islets.

RNA extraction and cDNA synthesis Total RNA was isolated using the RNAeasy kit (Qiagen, Los Angeles, CA, USA). Samples were treated with DNAse I (Ambion, Austin, TX, USA) to remove traces of contaminating genomic DNA. The cDNA synthesis was carried out with oligo(dT) and SuperScript II reverse transcriptase enzyme (Invitrogen, Chicago, IL, USA).

Quantitative real-time polymerase chain reaction Mouse islet cDNA was amplified using a set of forward (CD40F) and reverse (CD40R) primers specific for exons 7 and 9 , respectively (CD40F: TGGTCATTCCTGTCGTGATG; and CD40R: GGCTCTGTCTTGGCTCATCT). Reactions in which the reverse transcriptase enzyme was omitted were included as negative control. To determine the proper parameters for the acquisition of the fluorescence data, we performed a preliminary melting curve analysis. The melting curve analysis was carried out by heating to $95^{\circ} \mathrm{C}$, cooling to $55^{\circ} \mathrm{C}$ at $20^{\circ} \mathrm{C} / \mathrm{s}$, followed by heating to $94^{\circ} \mathrm{C}$ at a much slower rate of $0.2^{\circ} \mathrm{C} / \mathrm{s}$ and acquiring fluorescence continuously. This analysis allows us to determine the melting temperatures specific for the PCR product of interest. Fluorescence data were collected at $1.5^{\circ} \mathrm{C}$ below the melting temperature $\left(T_{\mathrm{m}}\right)$ of the specific product to avoid the contribution of the fluorescence generated by nonspecific products. The identity of the PCR products was verified by electrophoresis on $1 \%$ agarose gels. PCR amplifications were performed in a fluorescence temperature cycler (LightCycler; Roche Molecular Biochemicals, Indianapolis, IN, USA) in a final volume of $20 \mu \mathrm{l}$ containing $3 \mathrm{mmol} / 1 \mathrm{MgCl}_{2}, 0.5 \mu \mathrm{mol} / \mathrm{l}$ of each primer, $2 \mu \mathrm{l}$ of ready-to-use reaction mix $10 \times$ DNA Master SYBR Green I (Roche Molecular Biochemicals) and the template. The reaction was preincubated for $5 \mathrm{~min}$ at room temperature with $0.55 \mu \mathrm{g}$ of TaqStart antibody (Clontech, Palo Alto, CA, USA). The amplification programme was as follows: transition rate of $20^{\circ} \mathrm{C} / \mathrm{s}$ for all steps involved; 1 cycle of denaturation at $94^{\circ} \mathrm{C}$ for 1 min; 45 cycles of denaturation at $94^{\circ} \mathrm{C}$ for $5 \mathrm{~s}$, annealing at $55^{\circ} \mathrm{C}$ for $5 \mathrm{~s}$, and extension at $72^{\circ} \mathrm{C}$ for $10 \mathrm{~s}$; acquisition of fluorescence by heating to $87^{\circ} \mathrm{C}$ for $1 \mathrm{~s}$. The melting curve analysis was carried out by heating to $95^{\circ} \mathrm{C}$, cooling to $55^{\circ} \mathrm{C}$ at $20^{\circ} \mathrm{C} / \mathrm{s}$, followed by heating to $94^{\circ} \mathrm{C}$ at a much slower rate of $0.2^{\circ} \mathrm{C} / \mathrm{s}$, and acquiring fluorescence continuously.

PCR of cDNA from human sorted beta cells PCR amplification of human CD40 transcripts was performed with forward primer ACAAATACTGCGACCCCAAC (spanning exons 3 and 4) and reverse primer AAAGACCAGC ACCAAGAGGA (exon 7). The PCR conditions were 1 cycle for 1 min at $95^{\circ} \mathrm{C}, 40$ cycles of $30 \mathrm{~s}$ at $95^{\circ} \mathrm{C}, 45 \mathrm{~s}$ at $55^{\circ} \mathrm{C}$, and $45 \mathrm{~s}$ at $72^{\circ} \mathrm{C}$. A final elongation of 3 min was performed at $72^{\circ} \mathrm{C}$. 
The amplicon of $404 \mathrm{bp}$ was cleaved by StuI, generating fragments of 104 and $300 \mathrm{bp}$. Reactions in which the reverse transcriptase enzyme was omitted were included as negative controls.

Immunohistochemistry NIT-1 cells were grown to confluence in chamber slides, washed with PBS, and fixed in formalin. Cells were stained using the $\mathrm{ABC}$ staining kit according to the manufacturer's instructions (Santa Cruz Biotechnology, Santa Cruz, CA, USA) with $5 \mu \mathrm{g} / \mathrm{ml}$ rabbit antimouse CD40 polyclonal antibody (L-17; Santa Cruz Biotechnology) as primary antibody. Negative controls included sections that were stained with an isotype control antibody and sections that were incubated with the secondary but not the primary antibody.

Immunofluorescence of mouse tissue The pancreata from $\mathrm{NOD}, \mathrm{C} 57 \mathrm{BL} / 6$ and BALB/c mice were fixed in Bouin's solution (Sigma-Aldrich) and embedded in paraffin. Tissue sections were incubated with $5 \mu \mathrm{g} / \mathrm{ml}$ of CD40 polyclonal antibody (rabbit antimouse) followed by an AlexaFluor488-conjugated goat antirabbit secondary antibody (Molecular Probes, Eugene, OR, USA). In double-staining experiments, sections were also stained with a guinea pig antiporcine insulin antibody (Zymed Laboratories, South San Francisco, CA, USA) or with a mouse antiporcine glucagon monoclonal antibody (mAb; K79bB10; SigmaAldrich) that cross-react with mouse insulin and glucagon, respectively. Insulin or glucagon staining was revealed by incubation with secondary antibody AlexaFluor568-conjugated goat anti-guinea pig and goat antimouse, respectively. Control reactions included staining with isotype controls and omission of the primary antibody, as well as mismatched combinations of primary and secondary antibodies. Immunofluorescence was analysed by confocal microscopy using a Zeiss LSM-510 laser scanning microscope (Carl Zeiss, Thornwood, NY, USA).

Immunostaining of human pancreatic tissue and isolated islets Pelleted human islets or human pancreas was snapfrozen in OCT (Sakura Finetek, Torrance, CA, USA) and sectioned. Sections were dried and washed in PBS prior to fixation in Histochoice Tissue Fixative (Amresco, Solon, $\mathrm{OH}$, USA). After washing in PBS the samples were treated with Universal blocker (Biogenex, San Ramon, CA, USA) to prevent non-specific reactions. Sections were incubated with a mouse antihuman CD40 mAb (MAB89; BeckmannCoulter, Hialeah, FL, USA), washed and incubated with a secondary goat antimouse Alexa Fluor488 conjugate. The staining for either insulin was performed following the same protocol, using goat antirabbit Alexa Fluor568 conjugate as secondary antibody.

Flow cytometry One million NIT-1 cells or mousedissociated islet cells were incubated with $1 \mu \mathrm{g} / 100 \mu \mathrm{l}$ fluorescein isothiocynate (FITC)-conjugated hamster antimouse CD40 mAb (HM40-3; BD/Pharmingen, San Diego, CA, USA) for $30 \mathrm{~min}$ on ice, washed, and evaluated by flow cytometry. Mouse and human islets were dissoci- ated into single-cell suspensions by incubating aliquots of approximately 500-1,000 IEQ in $1 \mathrm{ml}$ of an Accutase solution (Innovative Cell Technologies, San Diego, CA, USA) at $37^{\circ} \mathrm{C}$ for $5-15 \mathrm{~min}$ and subsequently dispersed by gentle pipetting. Human islet cells were incubated with $1 \mu \mathrm{mol} / 1$ Newport green (NG) (Molecular Probes) for $30-60 \mathrm{~min}$ at $37^{\circ} \mathrm{C}$ in PBS without $\mathrm{Ca}^{2+}$ and $\mathrm{Mg}^{2+}$. After washing, cells were incubated on ice for $20 \mathrm{~min}$ with anti-CD40 conjugated to allophycocyanin (APC) or anti-CD40-phycoerythrin (HB14; Caltech, CA, USA; and clone MAB89, Beckmann-Coulter), respectively. Finally, cells were stained with 7-aminoactinomycin D (7-AAD; Invitrogen, La Jolla, CA, USA) at a concentration of $10 \mu \mathrm{g} / \mathrm{ml}$. The DNA-binding dye 7-AAD is capable of staining dead cells, thus allowing for their selective exclusion. Flow cytometry analysis was performed using the CellQuest software on a FACScan instrument (Becton Dickinson, Mountain View, CA, USA).

Incubation of human islets with proinflammatory cytokines Handpicked human islets were treated overnight with a combination of IL- $1 \beta\left(5 \times 10^{4} \mathrm{U} / \mathrm{l}\right), \mathrm{IFN}-\gamma\left(10^{6} \mathrm{U} / \mathrm{l}\right)$ and TNF- $\alpha\left(10^{6} \mathrm{U} / \mathrm{l}\right)$. Islets were washed, dissociated and analysed by flow cytometry as described above.

Cell sorting After dissociation into single-cell suspensions, islet cells were stained with NG and 7-AAD. Cell sorting was performed by using a FACSvantage (Becton Dickinson). NG-bright and NG-dim/negative subsets were obtained.

Western blot Highly purified C57BL/6 islets and NIT-1 cells were washed with cold PBS and lysed in $2 \%$ SDS, Tris- $\mathrm{HCl} 60 \mathrm{mmol} / 1$ (pH 6.8) buffer, incubated at $95^{\circ} \mathrm{C}$, sonicated in a water bath at $37^{\circ} \mathrm{C}$ and centrifuged at high speed for $10 \mathrm{~min}$. Assessment of the total protein content was carried out with the BCA detection kit (Pierce Biotechnology, Rockford, IL, USA). Aliquots corresponding to $50 \mu \mathrm{g}$ of protein were subjected to electrophoresis on a $12 \%$ SDS-PAGE pre-cast gel (Bio-Rad, Hercules, CA, USA) and transferred electrophoretically to an Immobilon polyvinylidene difluoride membrane. The membranes were incubated with $5 \%$ non-fat dry milk in TBS $(20 \mathrm{mmol} / 1$ Tris, $500 \mathrm{mmol} / \mathrm{l} \mathrm{NaCl}$, pH 7.5) overnight at $4^{\circ} \mathrm{C}$ to block non-specific binding. Subsequently, the membranes were immunoblotted with 1:200 rabbit antimouse CD40 polyclonal antibody (L-17; Santa Cruz Biotechnology) followed by incubation with a secondary antirabbit horseradish peroxidase-conjugated antibody and chemiluminescent detection (Amersham Biosciences, San Francisco, CA, USA). The same membranes were stripped and re-probed with an antimouse beta-actin antibody 2066 (Sigma-Aldrich).

$N F-\kappa B$ reporter gene assay NIT- 1 aliquots of $3.0 \times 10^{4}$ cells were seeded in 96-well flat-bottomed plates. After $24 \mathrm{~h}$, NIT-1 cells were transiently cotransfected with two different luciferase reporter plasmids: pNF $\kappa B-L u c$ (BD Biosciences/Clontech) that contains four copies of the $\mathrm{kB}$ binding element upstream of the promoter region driving 
the firefly luciferase expression, and the reporter plasmid phRL-TK, that also encodes for the luciferase enzyme from Renilla reniformis under the control of the constitutive promoter from thymidine kinase (Promega, Madison, WI, USA). Transfection was performed using the Fugene 6 reagent (Roche Biochemicals) with a 3:1 ratio of liposomes to DNA. After $24 \mathrm{~h}$, control cells were left untreated, and the rest were incubated in the presence of an agonistic antimouse CD40 mAb (HM40-3, $10 \mu \mathrm{g} / \mathrm{ml}$ ) or an isotype-matched antibody (G235-1, $10 \mu \mathrm{g} / \mathrm{ml})$. As a positive control, cells were also treated with TNF- $\alpha$ $\left(10^{6} \mathrm{U} / \mathrm{l}\right.$; Roche Biochemicals). After $2 \mathrm{~h}$ of incubation at $37^{\circ} \mathrm{C}$, lysates were prepared with the Dual-GLO-luciferase assay system according to the manufacturer's instructions (Promega). Luciferase activities were measured in a luminometer (Wallac 1420 Victor $^{2}$; Perkin-Elmer, Fremont, CA, USA). Luminescence measurements were integrated over a period of $10 \mathrm{~s} /$ well. Ratios of firefly to renilla luciferase activities are expressed as relative to the activity of the transfected, non-activated control cells.

Statistical analysis When appropriate, results were analysed by Student's $t$-test. Group comparisons were performed using one-way ANOVA and Dunnett's method for a posteriori contrasts using Sigma-Stat 2 software. Values of $p<0.05$ were considered statistically significant.

\section{Results}

CD40 mRNA is expressed in mouse islets and NIT-1 cells To investigate whether the CD40 gene is transcribed in mouse pancreatic islets and in the NIT-1 insulinoma cell line, we isolated total RNA from handpicked NOD and C57BL/6 islets and NIT-1 cells. For NOD mice, we used 4-week-old animals to avoid the potential contribution to CD40 expression associated with the presence of infiltrating immune cells. Quantification of CD40 transcripts using real-time PCR revealed that the CD40 transcript is present in islets, and its levels of expression were comparable among NOD, C57BL/6 islets and NIT-1 cells (Fig. 1a, b). The identity of the RT-PCR product was confirmed by cleaving the amplicon with restriction enzyme NciI, generating fragments of the expected sizes (145 and 210 bp, Fig. 1a, inset).

CD40 protein is expressed by mouse beta cells Figure 2a shows that CD40 protein expression is detectable in both mouse pancreatic islets and NIT-1 cells by western blot. We also used immunohistochemistry to assess CD40 protein expression in mouse pancreatic sections and NIT-1 cells. Using the anti-CD40 polyclonal antibody L17 we observed specific staining in NIT-1 cells (Fig. 2b). Omitting primary antibody, staining was not observed (Fig. 2c). Isolated islets and islets in pancreatic tissue sections stained positive for CD40 (Fig. 2d, e). Preabsorption of the antibody with its target peptide completely prevented staining. Similar results were obtained with the antimouse CD40 mAb HM40-3 followed by an FITC-conjugated a
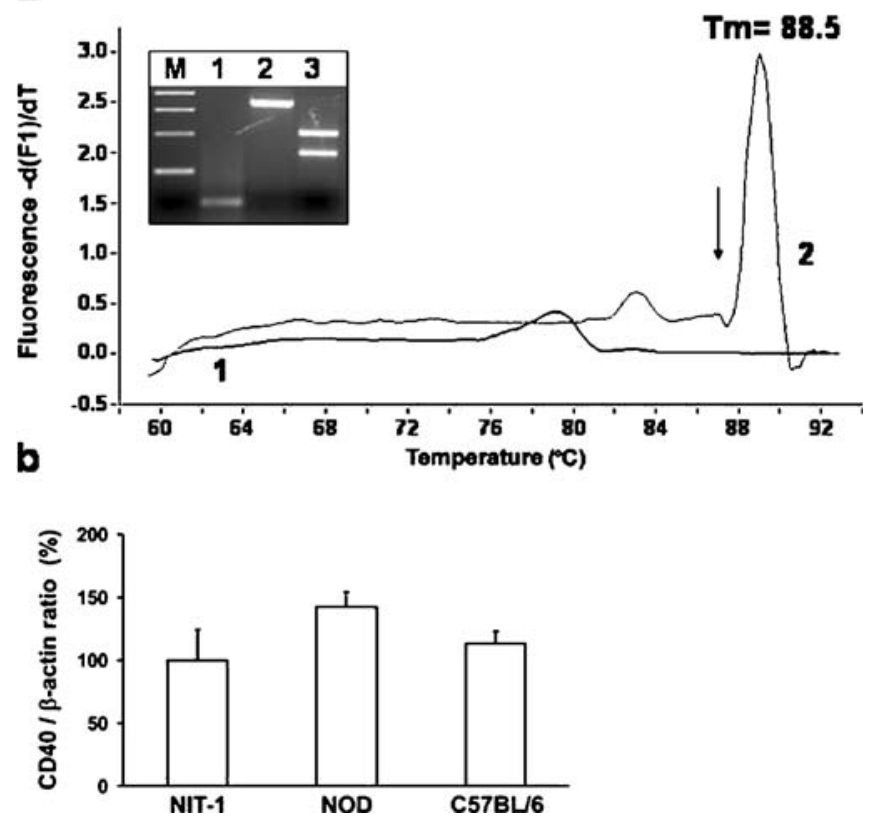

Fig. 1 Detection and quantification of CD40 transcripts in mouse islets and NIT-1 cells by RT-PCR. a Melting curve profile of CD40 transcripts using primers $\mathrm{CD} 40 \mathrm{~F}$ and $\mathrm{CD} 40 \mathrm{R}$, annealing to sequences from exon 7 and 9, respectively. Primers CD40F and CD40R generated CD40 amplicons of $355 \mathrm{bp}$. Melting curve analysis was carried out after CD40 amplification of cDNA from B6 islets. The first negative derivative of fluorescence vs time $(-\mathrm{d} F / \mathrm{d} T)$ is plotted against temperature. The CD40 product has a $T_{\mathrm{m}}$ of $88.5^{\circ} \mathrm{C}$. The arrow marks the temperature $\left(87^{\circ} \mathrm{C}\right)$ at which fluorescent data is acquired. 1 and 2 are the melting profile of amplification reactions from B6 islets (control no RT and plus RT reactions, respectively). Inset is an agarose gel electrophoresis of the CD40 amplicon. Lane M shows the 100-bp ladder DNA marker, lane 3 shows the restriction enzyme NciI of CD40 amplicon. b Ratio of levels of CD40 transcripts standardised by content of beta-actin transcripts from NIT-1 cells, 4-week-old NOD and C57BL/6. The results are the average of two experiments.

secondary antibody (data not shown). To define which mouse islet cell types express CD40, we used doubleimmunofluorescence staining. As shown in Fig. 3, laser confocal microscopy revealed that CD40 protein expression clearly colocalised with insulin but not with glucagon. We did not observe any appreciable differences in the staining patterns in pancreatic tissue sections from male or female $\mathrm{C} 57 \mathrm{BL} / 6, \mathrm{BALB} / \mathrm{c}$ or NOD mice (data not shown).

CD40 receptor is expressed on the surface of mouse islet cells Having demonstrated CD40 protein expression, we hypothesised that this receptor molecule may be present on the surface of islet cells. To test this hypothesis we analysed dissociated mouse islet cells and NIT-1 cells after incubation with the antimouse CD40 mAb HM40-3, directly conjugated with FITC (Fig. 4). Flow cytometry analysis revealed no staining with an isotype control antibody, while $58-85 \%$ of the dissociated islet cells and most of the NIT-1 cells exhibited surface staining for CD40. 

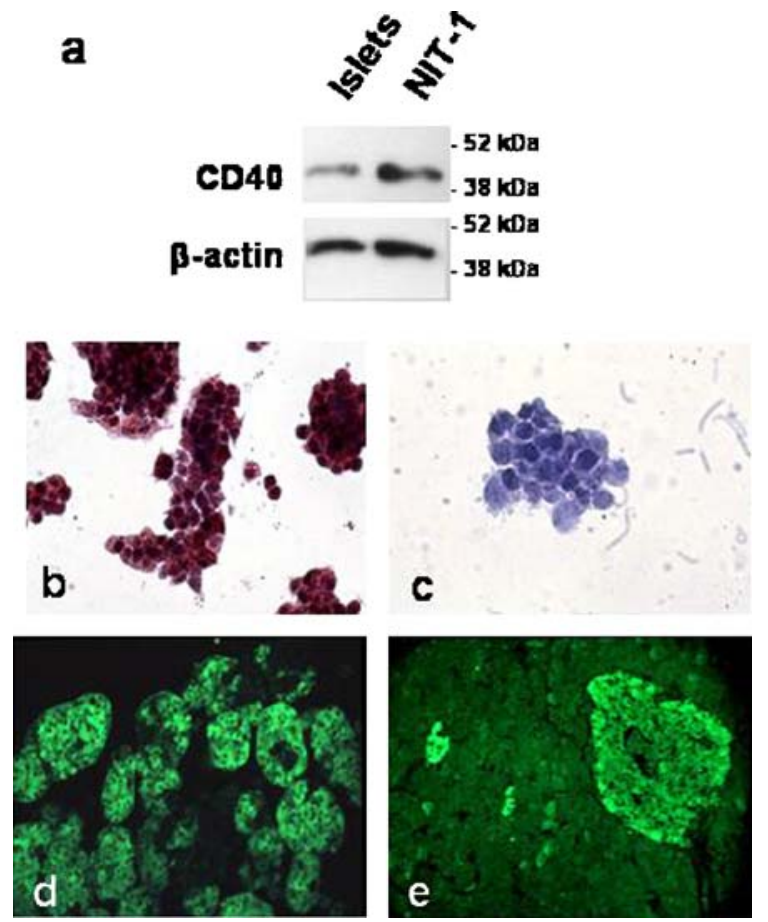

Fig. 2 Analysis of mouse CD40 expression by western blot and immunohistochemistry. a CD40 expression was analysed by Western blot on samples of C57BL/6 pancreatic islets and NIT-1 cells. The same gel was stripped and used for staining with a mouse antibody against actin, to ensure similar amounts of proteins were transferred and used for analysis. The locations of $52-$ and $38-\mathrm{kDa}$ protein markers are noted. Representative data from three experiments are shown. b NIT-1 cells were stained with a rabbit polyclonal antibody against CD40 and a biotinylated secondary antibody using the immunoperoxidase method and a streptavidin peroxidase conjugate DAB as a substrate. c NIT-1 cells stained in the absence of the primary antibody. d Paraffin sections of C57BL/6 isolated islets and pancreatic tissue (e) were stained with the same antibody followed by a secondary antibody conjugate with AlexaFluor488. Original magnification $(\mathbf{b}, \mathbf{c}, \mathbf{d}, \mathbf{e}) \times 20$. Representative data from five experiments are shown.

Fig. 3 Colocalisation of CD40 expression and insulin in pancreatic islets. Laser scanning confocal microscopy analysis of paraffin sections of pancreas from an 8-week-old BALB/c mouse stained for glucagon or insulin (red) or CD40 (green), or for CD40 and glucagon or CD40 and insulin, using double immunofluorescence. The far right column shows the superimposed stack optical sections of CD40 and glucagon or insulin staining. The resultant yellow colour indicates colocalisation of CD40 and insulin. Original magnification $\times 40$. Representative data from five experiments are shown.
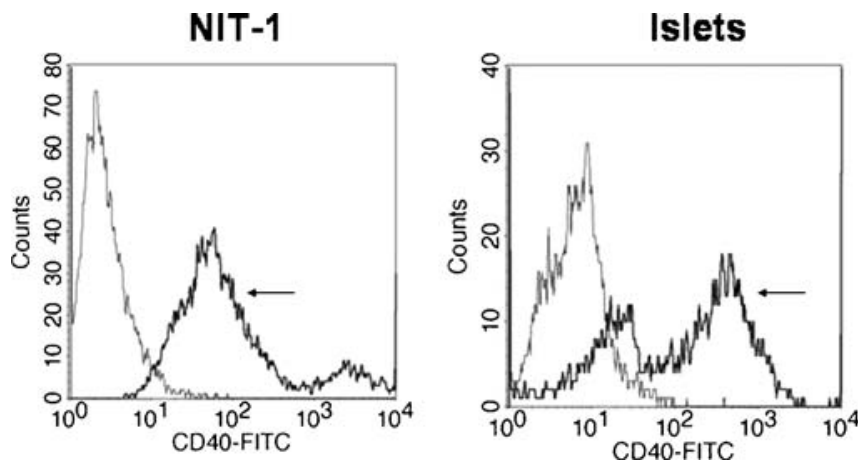

Fig. 4 CD40 expression in NIT-1 cells and isolated pancreatic islets. CD40 expression was analysed by flow cytometry in dispersed pancreatic islets isolated from C57BL/6 mice and NIT-1 cells. Curves show the profile of cells stained with an isotype-matched antibody and with anti-CD40-FITC HM40-3 antibody (arrow). Representative data from five experiments are shown.

CD40 is expressed by human beta cells We investigated whether the CD40 gene is also expressed in purified human islets following isolation with standard procedures. To ensure that we had pure preparations of islet cells, we stained islets with NG and 7-AAD, so that live beta cells could be identified and sorted [36]. NG-positive sorted cells are mostly $(90 \%)$ beta cells as assessed by insulin staining of sorted cells using immunohistochemistry (H. Ichii, unpublished observations). Similar to our findings in mouse islets, we detected CD40 transcripts in sorted human beta cells (Fig. 5a, inset). The identity of CD40 amplicon was confirmed by cleaving the 404-bp product with the restriction enzyme StuI, generating the expected fragments of 104 and $300 \mathrm{bp}$ (data not shown). We then assessed CD40 protein expression in isolated human islets by double-immunofluorescence staining. As shown in Fig. 5b, CD40 expression is detected by antibody staining and colocalises with insulin staining. Figure 5a demonstrates that CD40 is expressed on the 
$\mathbf{a}$

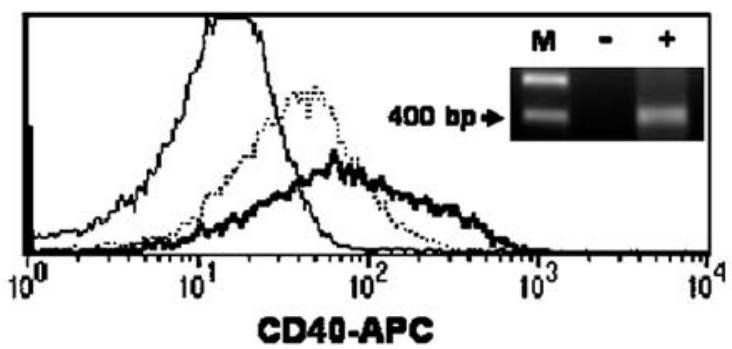

b
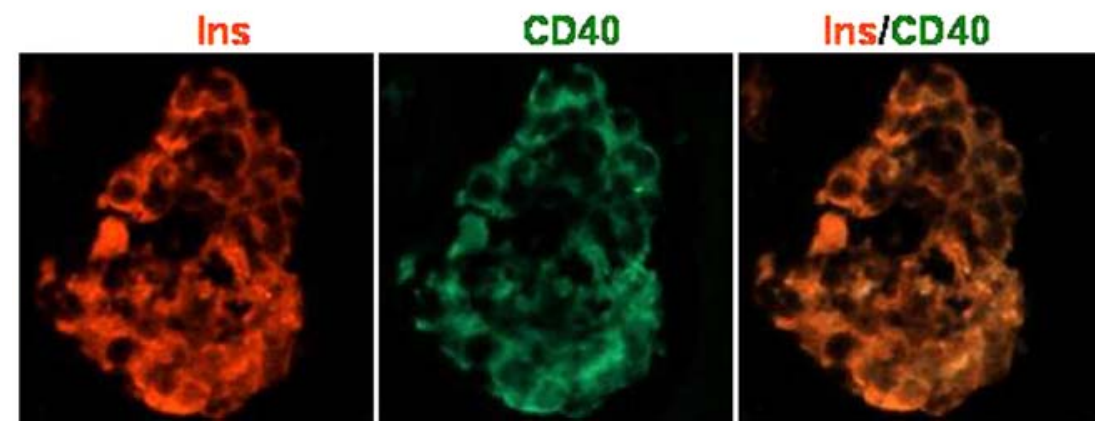

Fig. 5 Analysis of CD40 expression in human pancreatic islets. a Human islets were cultured overnight alone or with a combination of cytokines (IL- $1 \beta$, IFN- $\gamma$ and TNF- $\alpha$ ). Following dissociation, cells were stained with an APC-conjugated antihuman CD40 antibody (HB14) and fluorescence was analysed in the 7AAD-negative, Newport green-bright cell subset (live beta cells). Solid line represents fluorescence corresponding to control cells using isotype control antibody. Dotted and bold solid lines represent cell fluorescence from control or cytokine-treated islets using anti-CD40 HB14 antibody, respectively. Shown in the inset

surface of human islet cells that are 7-AAD-negative and NG-bright. Staining was observed with the antihuman CD40 mAb HB14 conjugated with APC and with the antiCD40 mAb MAB89 (data not shown). Thus, sorted islet cell populations highly enriched in beta cells expressed the CD40 transcript (Fig. 5a, inset) and protein, which, consistent with its receptor function, is expressed on the cell surface.

CD40 expression is upregulated by proinflammatory cytokines We treated human islets with a combination of proinflammatory cytokines that are reportedly associated with beta cell damage in autoimmune diabetes [37, 38]. Overnight incubation with a combination of IL-1 $\beta$ $\left(5 \times 10^{4} \mathrm{U} / \mathrm{l}\right), \mathrm{IFN}-\gamma\left(10^{6} \mathrm{U} / \mathrm{l}\right)$ and TNF- $\alpha\left(10^{6} \mathrm{U} / \mathrm{l}\right)$ upregulated CD40 expression in human beta cells (7-AADnegative/NG-bright positive) as shown by an increase in the median fluorescence intensity from $37.5 \pm 2.9$ in control cells to $67.3 \pm 6.8$ in the cytokine-treated cells $(p=0.02)$ (Fig. 5a).

CD40 receptor is functionally active CD40 signalling is known to activate the NF- $\mathrm{KB}$ transcription factor [14]. To investigate whether CD40 is functionally active in beta cells, we assessed NF-kB activation upon CD40 stimula- is an agarose gel with the RT-PCR CD40 transcript analysis from cDNA derived from sorted beta cells. b Frozen sections of isolated human islets were fixed and washed in PBS. After blocking with universal blocker and protein blocker, the sections were incubated with primary antihuman CD40 antibody MAB89 (host mouse) for $2 \mathrm{~h}$ and then incubated with AlexaFluor488 goat antimouse secondary antibody. The second staining for insulin was performed on the same sections with rabbit anti-insulin primary antibody and goat antirabbit AlexaFluor568 secondary antibody.

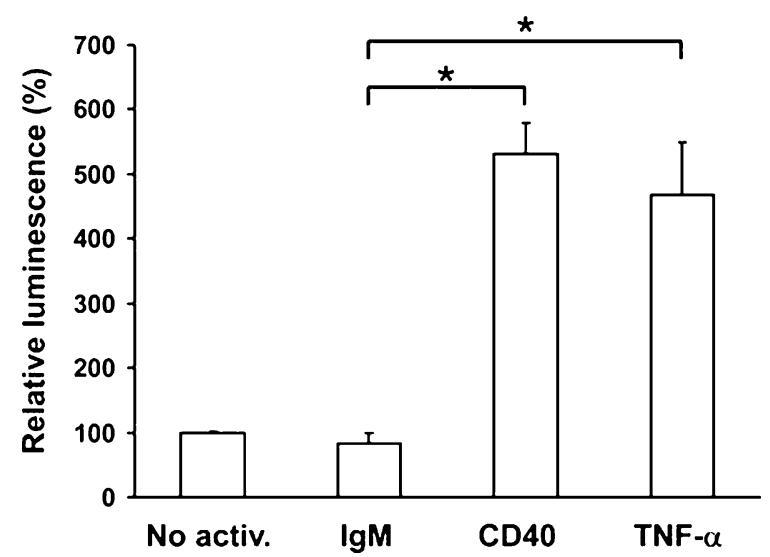

Fig. 6 CD40 receptor is functionally active, signalling through the activation of NF- $\mathrm{KB}$ transcription factor. NIT-1 cells were transfected with $1.0 \mu \mathrm{g}$ of the pNF-KB-luc reporter plasmid and $0.5 \mu \mathrm{g}$ of the control plasmid-expressing renilla luciferase. Twenty-four hours after transfection, cells were stimulated with CD40 antibody or the control isotype (IgM) for $2 \mathrm{~h}$. As a positive control, NIT-1 cells were activated with TNF- $\alpha$. Luciferase activity was determined as described in "Methods" and expressed as a ratio of the activity of firefly to renilla luciferase. Results are shown as a percentage relative to the control, where luciferase activity in the lysates of transfected, non-activated cells was taken to be $100 \%$. The values are expressed as means $\pm \mathrm{SD} ;{ }^{*} p<0.05$ versus IgM-stimulated cells. Representative data from four experiments are shown. 
tion. NIT-1 cells were transiently transfected with a luciferase reporter gene fused to a minimal thymidine kinase promoter that was preceded by four NF-KB consensus binding sites arrayed in tandem. As shown in Fig. 6, activation of the CD40 receptor by incubation with the agonistic mouse anti-CD40 mAb HM40-3 resulted in NF-KB activation.

\section{Discussion}

In the present study we demonstrate that CD40 is expressed in human and mouse pancreatic islets and in NIT-1 insulinoma cells. RT-PCR rendered CD40 amplicons from sorted human beta cells, purified NOD and C57BL/6 islets and NIT-1 cells. CD40 was also expressed at the protein level as demonstrated by immunohistochemistry and immunofluorescence. The observed colocalisation with insulin indicates that CD40 is expressed by beta cells in all mouse strains studied and in humans. The lack of colocalisation of CD40 and glucagon in mouse pancreatic tissue sections suggests that alpha cells do not express CD40.

We used flow cytometry to demonstrate that, consistent with its receptor function, CD40 was present at the cell surface. This was shown for both mouse and human islets. Agreeing with the double-immunofluorescence data, surface staining was observed in human islet cell preparations highly enriched in beta cells by staining with Newport green.

CD40 expression was upregulated by incubation of islets with a cocktail of cytokines which are known to be associated with autoimmune beta cell damage. Our finding that CD40 expression in human pancreatic beta cells is modulated by cytokines corroborates a previous report from Cardozo et al. [39] describing CD40 as one of the genes being activated by cytokines in primary rat beta cells. Furthermore, our data in NIT-1 cells suggest that islet cells express a functional CD40 receptor, the triggering of which results in activation of NF- $\mathrm{KB}$. This is a well-known consequence of CD40 signalling. Indeed, CD40 and other members of the TNFR family lack intrinsic kinase activity in the cytoplasmic tail, but propagate signals by associating with TNFR-associated factors (a family of adaptor proteins) [14] which in turn activate NF- $\mathrm{KB}$ and the AP-1 transcription factor complex.

It was recently reported that CD40 is expressed in human pancreatic duct cells but not in islets when expression was analysed by immunohistochemistry on pancreatic sections [24]. Our data demonstrating CD40 expression in human beta cells after isolation (as assessed by RT-PCR, double-immunofluorescence staining of isolated human islets and flow cytometry) suggest that CD40 expression in human beta cells may be induced by the manipulation associated with the islet isolation process. In addition, we show that incubation with cytokines increases CD40 expression by human beta cells. However, CD40 was constitutively expressed in mouse islets. Thus, our data highlight a possible difference in CD40 expression between mouse and human islets, and suggest that its expression is responsive to selected stimuli.

The above findings imply a potentially important role for islet cell CD40 expression in both physiological and pathophysiological conditions. In particular, human islet cell responsiveness to cytokines suggests that CD40 expression may play a significant role during inflammatory conditions such as the development of autoimmune diabetes or in the transplantation setting. Perhaps CD40 expression by islets can play a role similar to that of other costimulatory molecules. For example, the transgenic expression of the costimulatory molecule B7-1 on the surface of beta cells results in accelerated diabetes in NOD mice $[40,41]$. Transgenic mice expressing B7-1 and the lymphocytic choriomeningitis virus (LCMV) glycoprotein in islets and having T cells with a glycoprotein-specific T-cell receptor develop autoimmune diabetes following exposure to LCMV [42]. Mice expressing B7-1 and human HLADQ molecules associated with increased diabetes risk also develop autoimmune diabetes [43]. It is therefore plausible that the constitutive and selective expression of CD40 on the surface of beta cells may contribute to autoimmunity by providing costimulatory signals to infiltrating lymphocytes. In light of our findings, the inhibition of spontaneous diabetes reported in NOD mice treated with anti-CD154 antibody (anti-CD40L) [13] might be explained not only as a result of costimulatory blockade in APCs but also in beta cells. Likewise, blockade of the CD40 pathway promotes islet allograft survival in rodent transplantation models [44], and this effect could be partially dependent on the blockade of CD40 signalling in beta cells.

Further studies will be necessary to fully assess the potential role of CD40 in the mediation of proinflammatory signals. CD40 knockout mice have been generated [45], and these mice are functionally deficient in CD40 function in all the cells that express CD40. Therefore, these mice are not suitable to selectively study the effects of CD40 expression and its inhibition in beta cells and immune cells. The generation of knockout mice selectively lacking CD40 expression in either islets or bone marrow-derived cells and backcrossing into NOD mice will be required to better characterise the functional role of CD40 expression in pancreatic beta cells, a phenomenon that was previously unrecognised.

Acknowledgements This work was supported by the Diabetes Research Institute Foundation. F. Barbé-Tuana is supported by the Brazilian Foundation CAPES. We thank the Imaging Core at the University of Miami, partly supported by a centre grant from the Juvenile Diabetes Research Foundation (JDRF), for providing access to confocal microscopy.

\section{References}

1. Stamenkovic I, Clark EA, Seed B (1989) A B-lymphocyte activation molecule related to the nerve growth factor receptor and induced by cytokines in carcinomas. EMBO J 8:14031410 
2. Hollenbaugh D, Grosmaire LS, Kullas CD et al (1992) The human T cell antigen gp39, a member of the TNF gene family, is a ligand for the CD40 receptor: expression of a soluble form of gp39 with B cell co-stimulatory activity. EMBO J 11:43134321

3. Armitage RJ, Fanslow WC, Strockbine L et al (1992) Molecular and biological characterization of a murine ligand for CD40. Nature 357:80-82

4. Grewal IS, Flavell RA (1998) CD40 and CD154 in cellmediated immunity. Annu Rev Immunol 16:111-135

5. Klaus SJ, Berberich I, Shu G, Clark EA (1994) CD40 and its ligand in the regulation of humoral immunity. Semin Immunol 6:279-286

6. Yang Y, Wilson JM (1996) CD40 ligand-dependent T cell activation: requirement of B7-CD28 signaling through CD40. Science 273:1862-1864

7. Lenschow DJ, Walunas TL, Bluestone JA (1996) CD28/B7 system of T cell costimulation. Annu Rev Immunol 14:233-258

8. Larsen CP, Alexander DZ, Hollenbaugh D et al (1996) CD40gp39 interactions play a critical role during allograft rejection: suppression of allograft rejection by blockade of the CD40gp39 pathway. Transplantation 61:4-9

9. Parker DC, Greiner DL, Phillips NE et al (1995) Survival of mouse pancreatic islet allografts in recipients treated with allogeneic small lymphocytes and antibody to CD40 ligand. Proc Natl Acad Sci U S A 92:9560-9564

10. Kirk AD, Harlan DM, Armstrong NN et al (1997) CTLA4-Ig and anti-CD40 ligand prevent renal allograft rejection in primates. Proc Natl Acad Sci U S A 94:8789-8794

11. Kenyon NS, Chatzipetrou M, Masetti M et al (1999) Long-term survival and function of intrahepatic islet allografts in rhesus monkeys treated with humanized anti-CD154. Proc Natl Acad Sci U S A 96:8132-8137

12. Mohan C, Shi Y, Laman JD, Datta SK (1995) Interaction between CD40 and its ligand gp39 in the development of murine lupus nephritis. J Immunol 154:1470-1480

13. Balasa B, Krahl T, Patstone G et al (1997) CD40 ligand-CD40 interactions are necessary for the initiation of insulitis and diabetes in nonobese diabetic mice. J Immunol 159:4620-4627

14. van Kooten C, Banchereau J (2000) CD40-CD40 ligand. J Leukoc Biol 67:2-17

15. Calderhead DM, Kosaka Y, Manning EM, Noelle RJ (2000) CD40-CD154 interactions in B-cell signaling. Curr Top Microbiol Immunol 245:73-99

16. Rathmell JC, Townsend SE, Xu JC, Flavell RA, Goodnow CC (1996) Expansion or elimination of B cells in vivo: dual roles for CD40- and Fas (CD95)-ligands modulated by the B cell antigen receptor. Cell 87:319-329

17. Wagner DH Jr, Vaitaitis G, Sanderson R, Poulin M, Dobbs C, Haskins K (2002) Expression of CD40 identifies a unique pathogenic T cell population in type 1 diabetes. Proc Natl Acad Sci U S A 99:3782-3787

18. Karmann K, Hughes CC, Schechner J, Fanslow WC, Pober JS (1995) CD40 on human endothelial cells: inducibility by cytokines and functional regulation of adhesion molecule expression. Proc Natl Acad Sci U S A 92:4342-4346

19. Galy AH, Spits H (1992) CD40 is functionally expressed on human thymic epithelial cells. J Immunol 149:775-782

20. Tan J, Town T, Mori T et al (2002) CD40 is expressed and functional on neuronal cells. EMBO J 21:643-652

21. Smith TJ, Sciaky D, Phipps RP, Jennings TA (1999) CD40 expression in human thyroid tissue: evidence for involvement of multiple cell types in autoimmune and neoplastic diseases. Thyroid 9:749-755

22. Sugimoto K, Shiraki K, Ito T et al (1999) Expression of functional CD40 in human hepatocellular carcinoma. Hepatology 30:920-926

23. Hess S, Engelmann H (1996) A novel function of CD40: induction of cell death in transformed cells. J Exp Med 183:159167
24. Vosters O, Beuneu C, Nagy N et al (2004) CD40 expression on human pancreatic duct cells: role in nuclear factor-kappa $B$ activation and production of pro-inflammatory cytokines. Diabetologia 47:660-668

25. Ghia P, Boussiotis VA, Schultze JL et al (1998) Unbalanced expression of bcl-2 family proteins in follicular lymphoma: contribution of CD40 signaling in promoting survival. Blood 91:244-251

26. Hess S, Gottfried E, Smola H, Grunwald U, Schuchmann M, Engelmann H (1998) CD40 induces resistance to TNF-mediated apoptosis in a fibroblast cell line. Eur J Immunol 28:3594-3604

27. Wingett DG, Vestal RE, Forcier K, Hadjokas N, Nielson CP (1998) CD40 is functionally expressed on human breast carcinomas: variable inducibility by cytokines and enhancement of Fas-mediated apoptosis. Breast Cancer Res Treat 50:27-36

28. Gallagher NJ, Eliopoulos AG, Agathangelo A, Oates J, Crocker J, Young LS (2002) CD40 activation in epithelial ovarian carcinoma cells modulates growth, apoptosis, and cytokine secretion. Mol Pathol 55:110-120

29. Nadeau S, Rivest S (1999) Effects of circulating tumor necrosis factor on the neuronal activity and expression of the genes encoding the tumor necrosis factor receptors (p55 and p75) in the rat brain: a view from the blood-brain barrier. Neuroscience 93:1449-1464

30. Chao MV (1994) The p75 neurotrophin receptor. J Neurobiol 25:1373-1385

31. Stephens LA, Thomas HE, Ming L et al (1999) Tumor necrosis factor-alpha-activated cell death pathways in NIT-1 insulinoma cells and primary pancreatic beta cells. Endocrinology 140:3219-3227

32. Kanaka-Gantenbein C, Dicou E, Czernichow P, Scharfmann R (1995) Presence of nerve growth factor and its receptors in an in vitro model of islet cell development: implication in normal islet morphogenesis. Endocrinology 136:3154-3162

33. Scharfmann R, Tazi A, Polak M, Kanaka C, Czernichow P (1993) Expression of functional nerve growth factor receptors in pancreatic beta-cell lines and fetal rat islets in primary culture. Diabetes 42:1829-1836

34. Ricordi C, Lacy PE, Finke EH, Olack BJ, Scharp DW (1988) Automated method for isolation of human pancreatic islets. Diabetes 37:413-420

35. Bottino R, Fernandez LA, Ricordi C et al (1998) Transplantation of allogeneic islets of Langerhans in the rat liver: effects of macrophage depletion on graft survival and microenvironment activation. Diabetes 47:316-323

36. Lukowiak B, Vandewalle B, Riachy R et al (2001) Identification and purification of functional human beta-cells by a new specific zinc-fluorescent probe. J Histochem Cytochem 49:519528

37. Toyoda H, Formby B, Magalong D et al (1994) In situ islet cytokine gene expression during development of type I diabetes in the non-obese diabetic mouse. Immunol Lett 39:283-288

38. Eizirik DL, Mandrup-Poulsen T (2001) A choice of death-the signal-transduction of immune-mediated beta-cell apoptosis. Diabetologia 44:2115-2133

39. Cardozo AK, Heimberg H, Heremans Y et al (2001) A comprehensive analysis of cytokine-induced and nuclear factorkappa B-dependent genes in primary rat pancreatic beta-cells. J Biol Chem 276:48879-48886

40. Wong S, Guerder S, Visintin I et al (1995) Expression of the costimulator molecule B7-1 in pancreatic beta-cells accelerates diabetes in the NOD mouse. Diabetes 44:326-329

41. Wong FS, Visintin I, Wen L, Granata J, Flavell R, Janeway CA (1998) The role of lymphocyte subsets in accelerated diabetes in nonobese diabetic-rat insulin promoter-B7-1 (NOD-RIP-B7-1) mice. J Exp Med 187:1985-1993 
42. Harlan DM, Hengartner H, Huang ML et al (1994) Mice expressing both B7-1 and viral glycoprotein on pancreatic beta cells along with glycoprotein-specific transgenic T cells develop diabetes due to a breakdown of T-lymphocyte unresponsiveness. Proc Natl Acad Sci U S A 91:3137-3141

43. Wen L, Wong FS, Tang J et al (2000) In vivo evidence for the contribution of human histocompatibility leukocyte antigen (HLA)-DQ molecules to the development of diabetes. J Exp Med 191:97-104
44. Phillips NE, Markees TG, Mordes JP, Greiner DL, Rossini AA (2003) Blockade of CD40-mediated signaling is sufficient for inducing islet but not skin transplantation tolerance. J Immunol 170:3015-3023

45. Kawabe T, Naka T, Yoshida K et al (1994) The immune responses in CD40-deficient mice: impaired immunoglobulin class switching and germinal center formation. Immunity $1: 167-178$ 